\title{
القيم التعبيرية للتصوير على الأسطح الخزفية خلال عصر النهضة
}

\author{
د. - أماني إبراهيم فرغل \\ مدرس التصوير بفسم التربية الفنية إنية \\ كلية التربية النوعية ـجامعة المنوفية الكربة المنة
}

د./ مند جمال إبراهيم بكري

مدرس الخزف بقسم التربية الفنية

كلية التربية النوعية ـ جامعة المنوفية الفية

\section{ملخص البحث}

خلفية البحث: يمثل التصوير علي الأسطح الخزفية أحد الظواهر التي تربط وتجمع بين

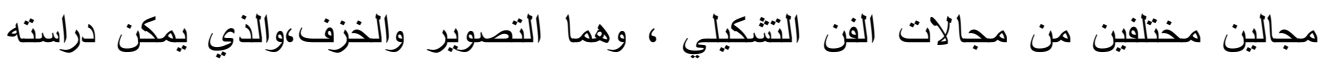
كظاهرة للوقوف علي مقومات فنية عديده ومتتوعية والتي تربط بأساليب وأنماط مختلفة للتعبير

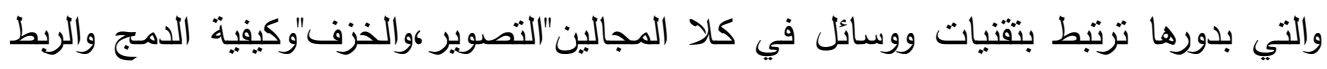
بين المجالين والوصول من خلالهما إلي قيم تعبيرية متنوعه .

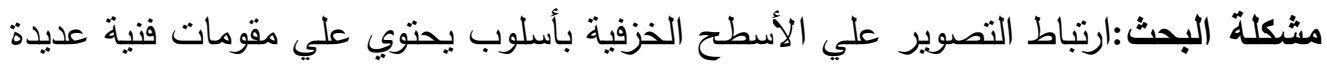

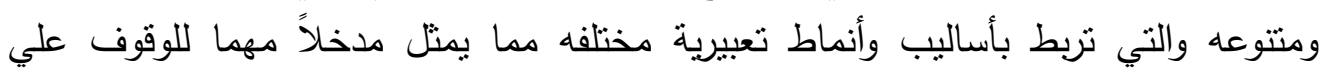

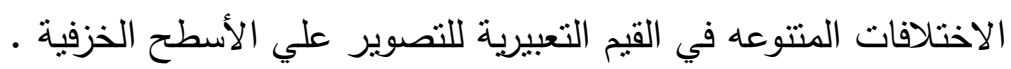

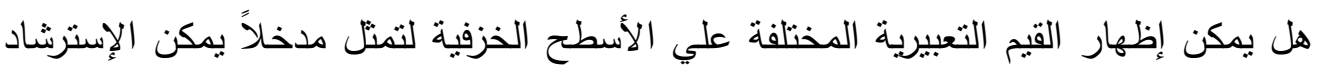

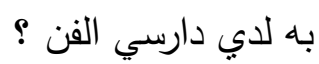
هدف البحث: الافادة من الجمع بين مجالي التصوير والخزف في إظهار القيم التعبيرية

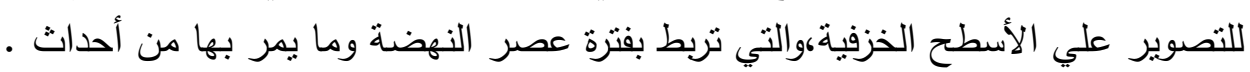

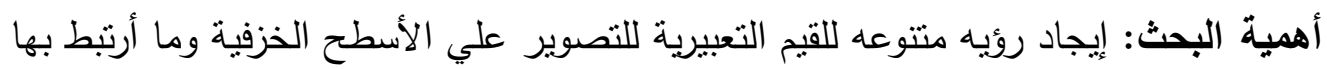

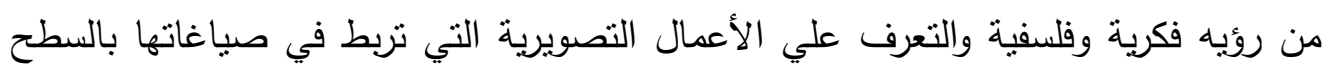

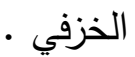

فروض البحث: يمكن الوصول لمنطلقات تتضمن طرق متتوعه ترتبط بالاساليب والانماط

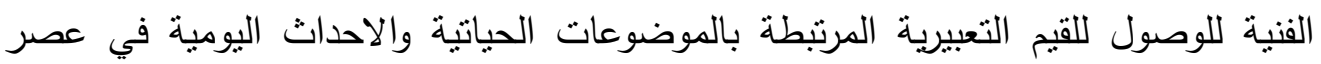

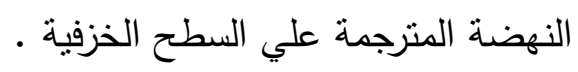
حدود البحث : يقتصر البحث علي القيم التعبيرية المصاغة علي الأسطح الخزفية في فترة

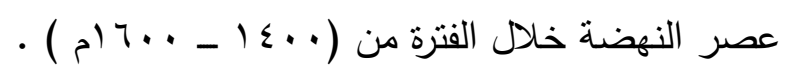
منهجية البحث: يتبع البحث المنهج الوصفي للقيم التعبيرية للتصوير علي النئ الأسطح الخزفية في

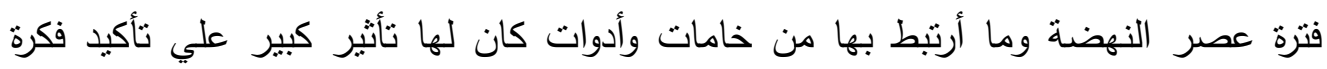

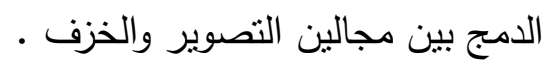




\section{Research Summary}

\section{Expressive Values of Imaging on Ceramic Surfaces During the Renaissance}

BACKGROUND: Photography on ceramic surfaces is one of the phenomena that connects and combines two different fields of plastic art, namely photography and ceramics, which can be studied as a phenomenon to find out the many and varied artistic elements that link different methods and patterns of expression, which in turn are related to techniques and means in both fields. Imaging, ceramics "and how to merge and link between the two fields and reach through them to various expressive values.

The problem of research: Correlation of imaging on ceramic surfaces in a manner that contains many technical elements and a variety of different methods and expressive patterns that represent an important entry to identify the differences in the expressive values of imaging on ceramic surfaces.

Can the different expressive values be shown on ceramic surfaces as an input to the art students?

Objective: To benefit from combining the fields of photography and ceramics in showing the expressive values of photography on ceramic surfaces, which relate to the period of the Renaissance and its events.

The importance of the research: Finding a diverse vision of the expressive values of imaging on ceramic surfaces and associated intellectual and philosophical insights and to identify the photographic work that links in its formulations to the ceramic surface.

\section{Research hypotheses:}

It is possible to reach the starting points include a variety of methods linked to methods and artistic patterns to access the expressive values associated with life topics and daily events in the Renaissance translated on the ceramic surface.

\section{Research limits:}

The research is limited to expressive values formulated on ceramic surfaces in the period of the Renaissance during the period (1400 1600) AD).

Research Methodology:

The research follows the descriptive approach of the expressive values of imaging on ceramic surfaces in the period of the Renaissance and the associated materials and tools have had a significant impact on the confirmation of the idea of combining the fields of imaging and ceramics. 
يمثل التصوير علي الاسطح الخزفية أحد الظواهر التي تربط وتجمع بين مجالين مختلفين

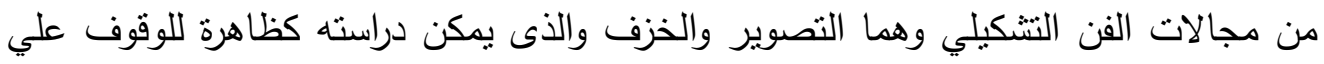

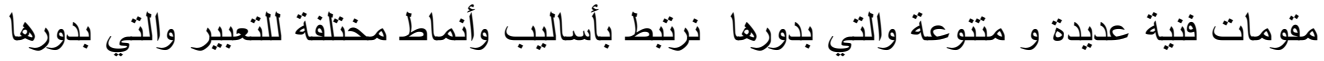

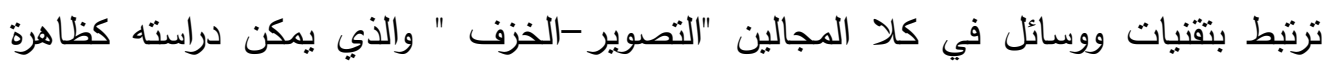

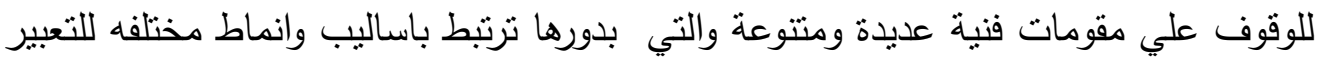

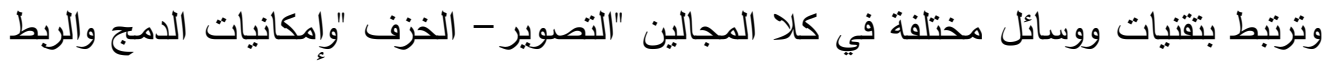
بين المجالين و الوصول من خلاتلهما الي قيم تعبيربيه متتوعه.

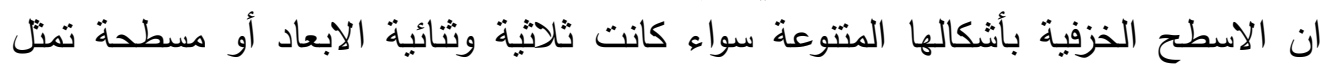

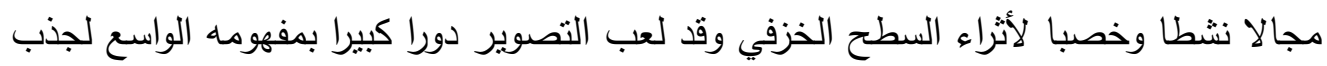
الفنانين لشغل هذا السطح والعمل عليه وتحقيق قيم تعبيريه من خلالها.

مشكله البحث

ارتبط التصوير على الاسطح الخزفية بأسلوب يحتوي على مقومات فنية عديده ومتتوعة

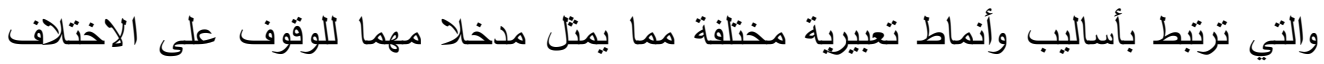

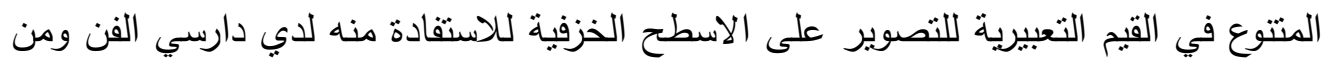

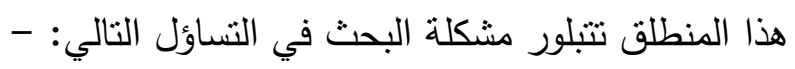

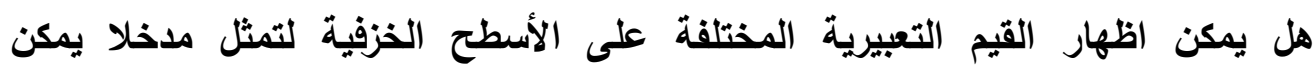
الاسترشاد به لاى دل دارسي الفن؟ هدف البحث 1- اظهار القيم التعبيرية المختلفة على الأسطح الخزفية في عصر النهضة.

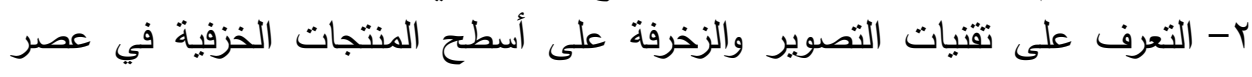
النهضة.

r- الإفادة من الجمع بين مجالي التصوير والخزف في إظهار القيم التعبيرية للتصوير

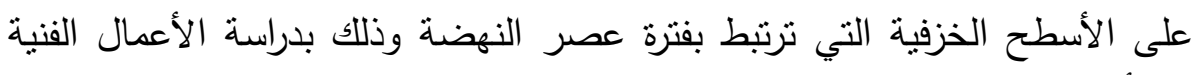

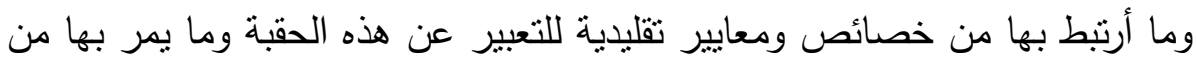

$$
\text { أحداث منتوعه. }
$$

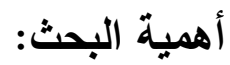

1- إيجاد رؤية متتوعة للقيم التعبيرية للتصوير على الأسطح الخزفية وما أرتبط بها من

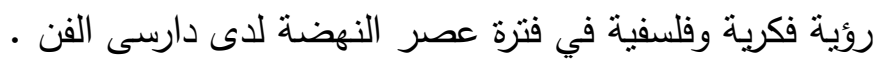

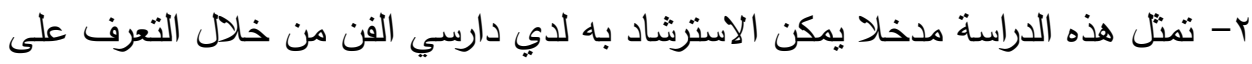

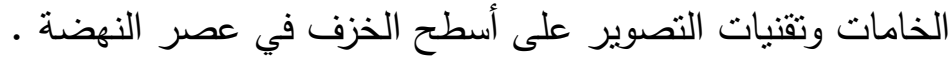


يمكن الوصول لمنطلقات تتضمن طرق منتوعة ترتبط بالأساليب والأنماط الفنية

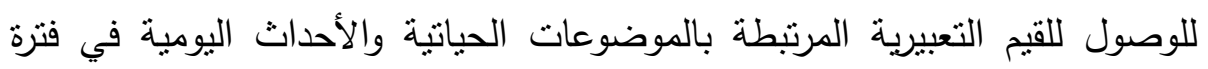
عصر النهضة المنرجمة على الأسطح الخزفية. حدود البحث :

أقتصرت الدراسة على عصر النهضة فيى الفترة من نهاية القرن بال إلى إلى القرن 10

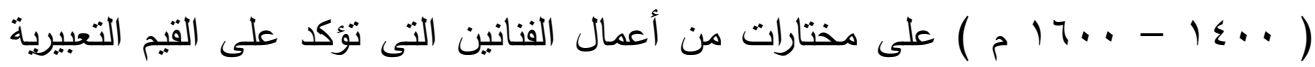

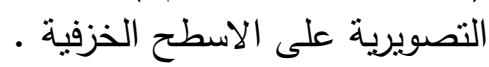
منهج البحث :

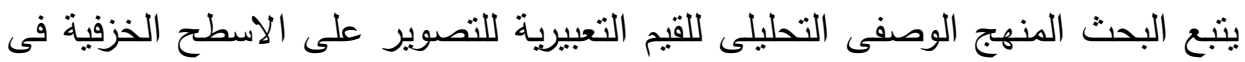

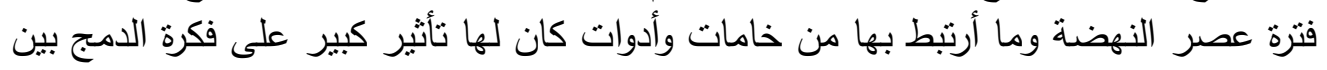

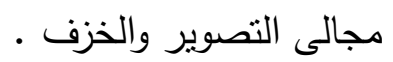

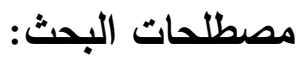

ا ـ القيم التعبيرية " Expressive Values " : تمثل القيمة الصفة التي تجعل الثيء مرغوبا

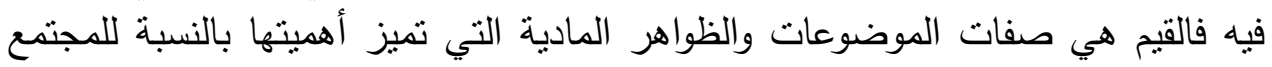

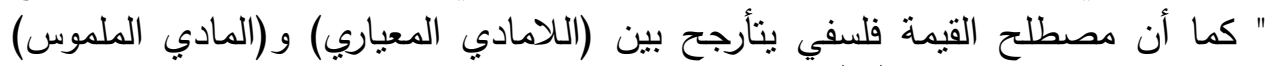

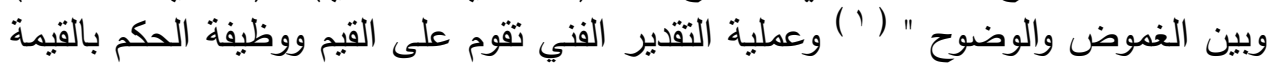

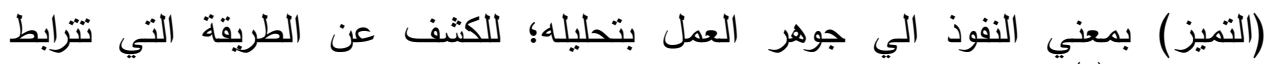

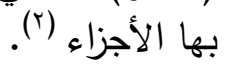

r. الأسطح الخزفية" Ceramic Surfaces " : هي الأسطح الخارجية لجميع الأعمال الخزفية

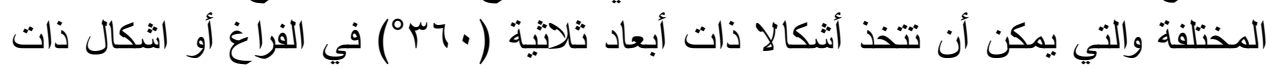

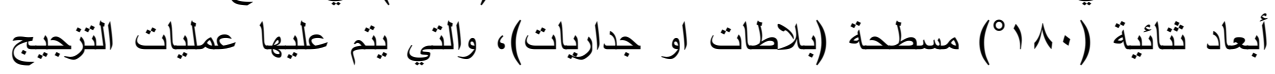

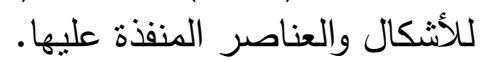

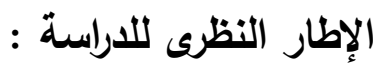

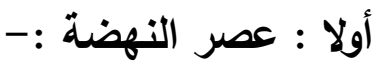

بدأ الطور الافتتاحي لعصر النهضة في ابطاليا، وكانت فترة تغير وانجازات ثقافية عظيمة

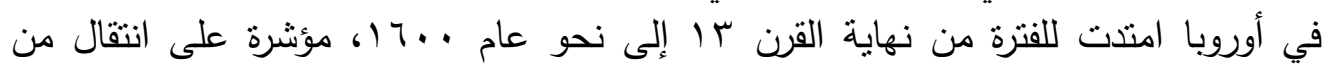

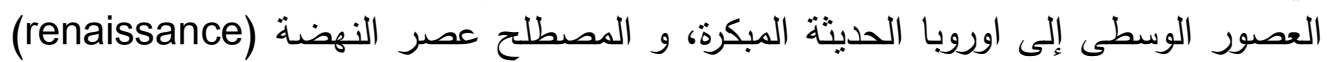

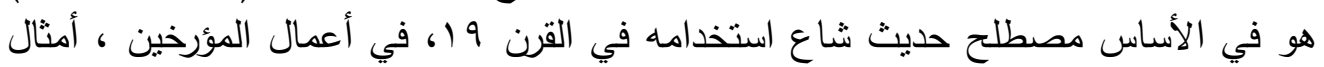

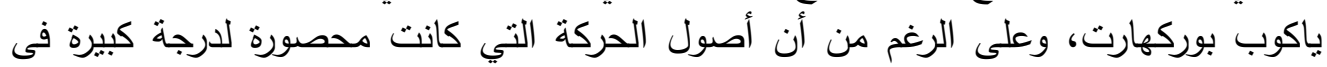

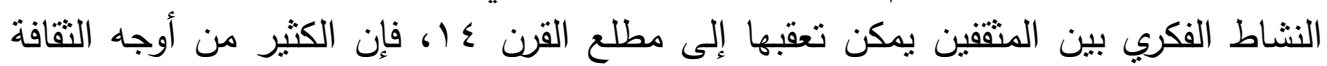

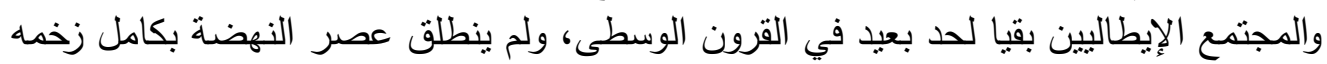
حتى نهاية القرن. 


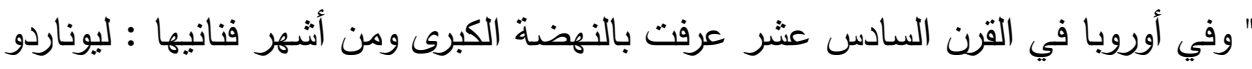

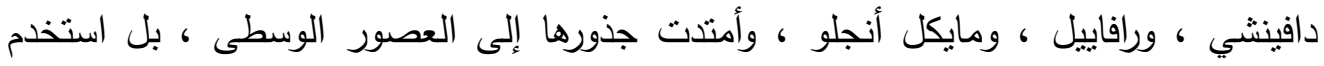

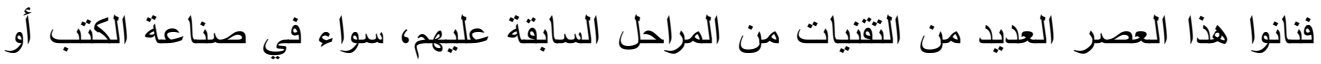

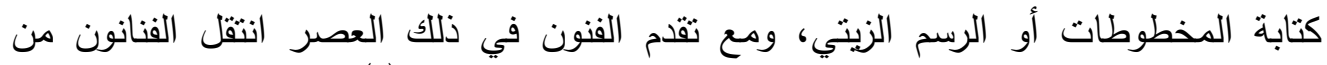

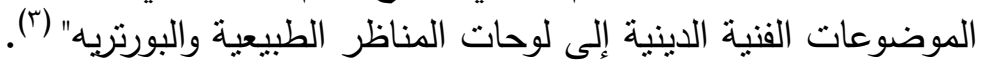

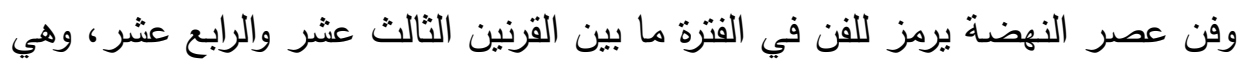

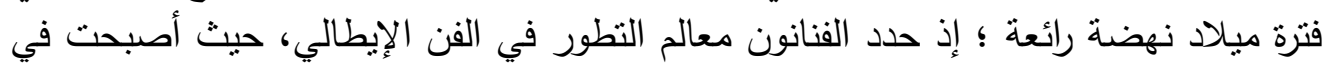

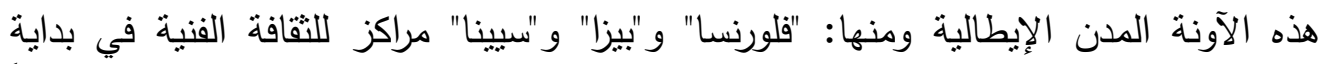

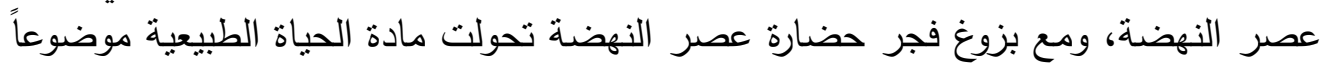

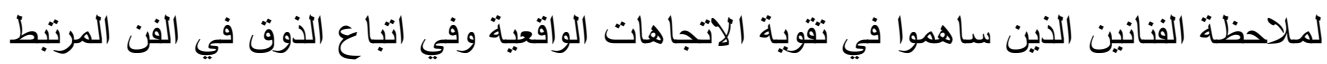

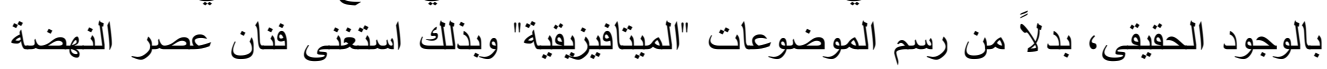

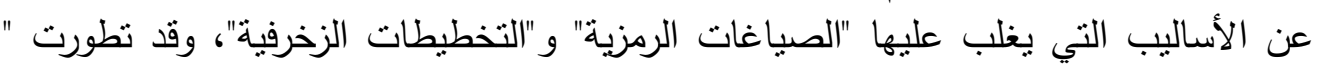

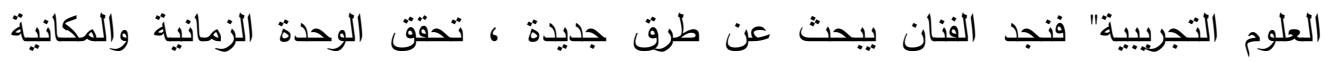

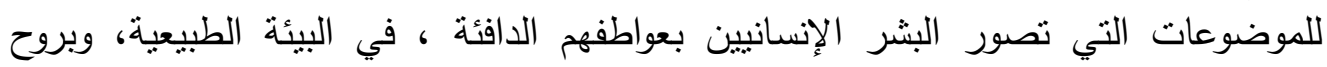

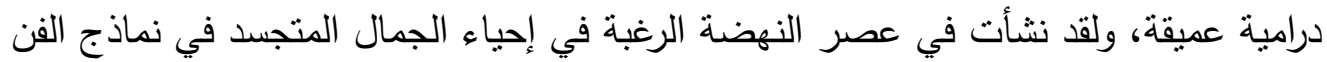

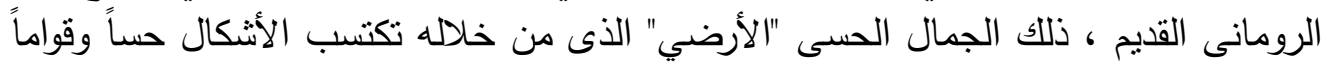

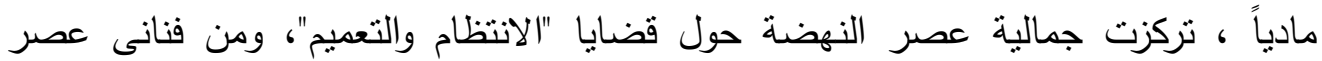

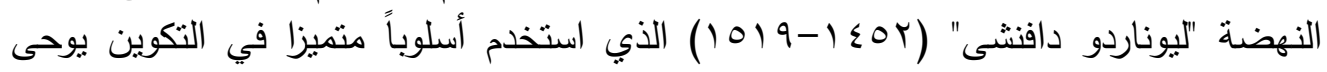

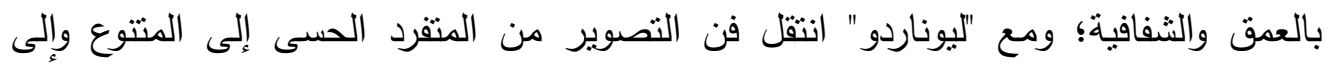

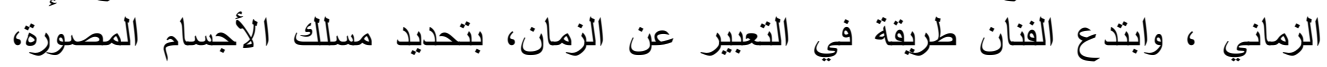

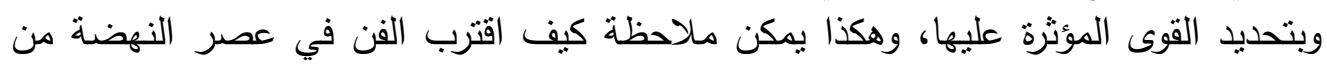

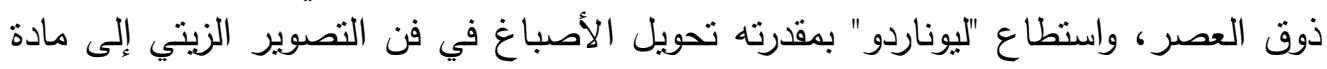

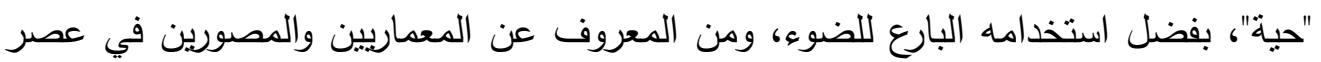

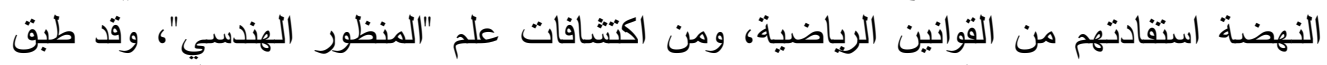

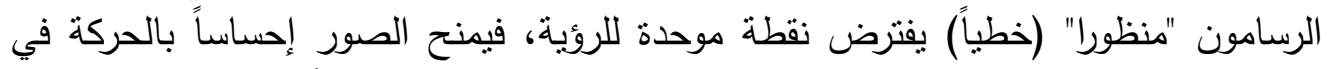

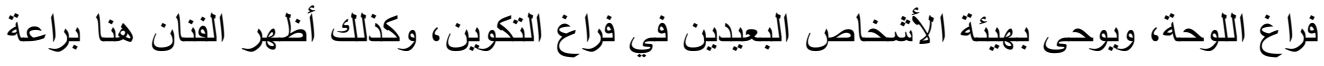

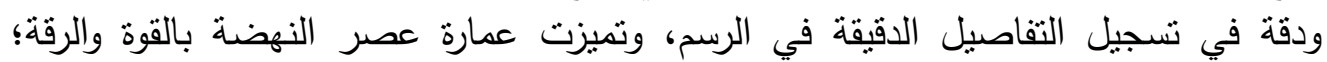

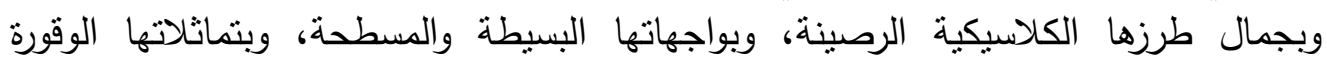

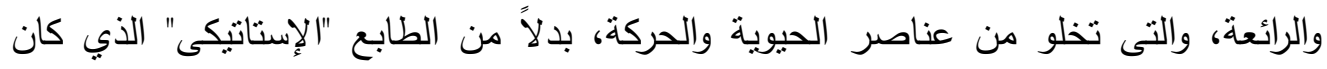

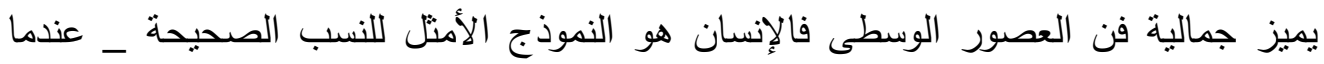
يبسط الإنسان ذراعيه وساقييه فإن الثكلين الهندسيين المثالين وهما المربع الإنيان والدائرة سيمثلان

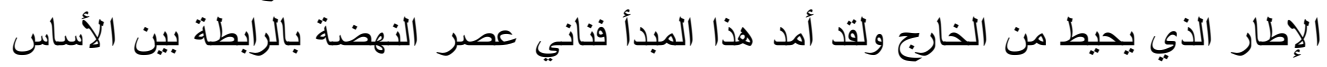

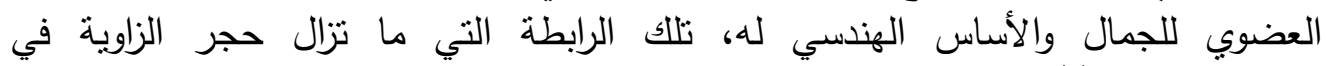

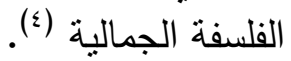




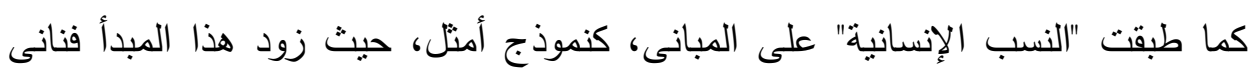

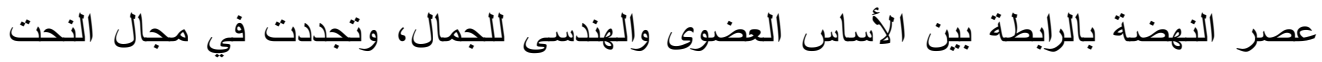

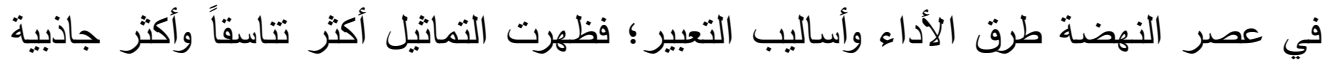

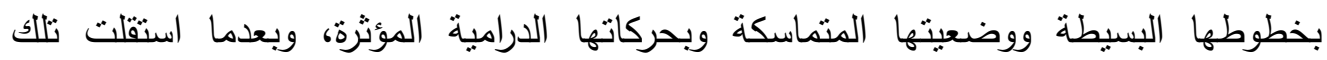

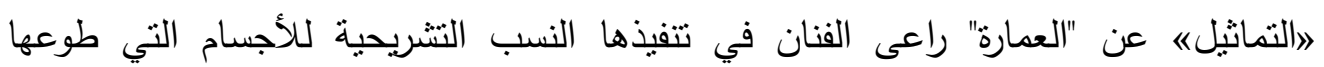

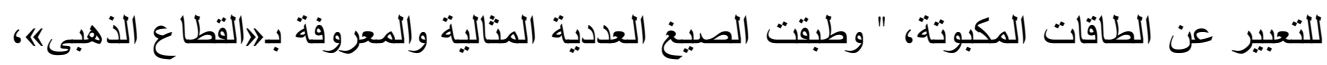

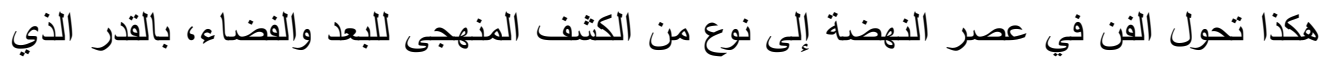

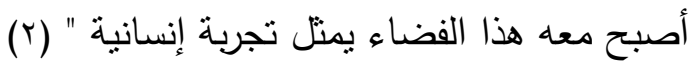
ثانيا : المايوليكا :

"يثير المصطلح الإيطالي مايوليكا على طريقة تتفيذ الزخارف والرسوم على الخزفيات

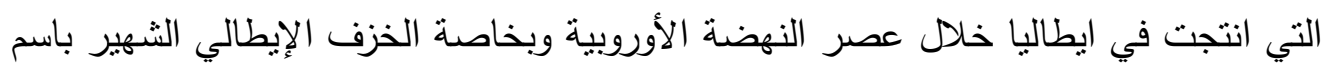

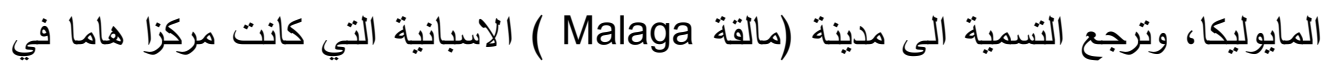

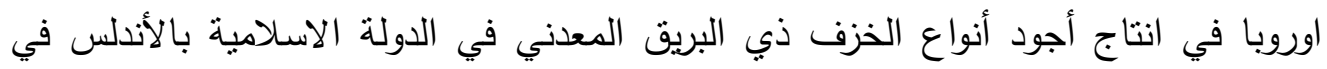

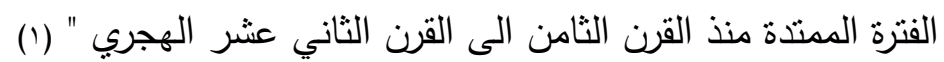

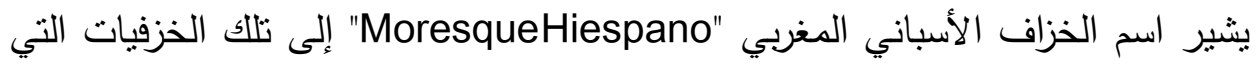

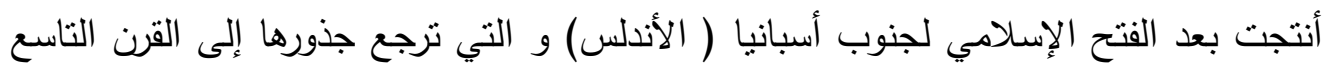

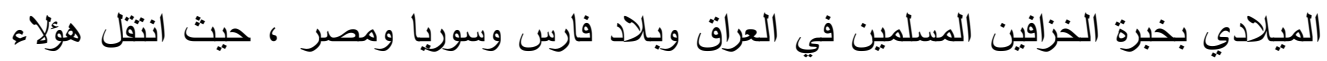

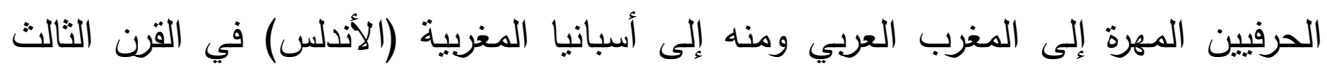

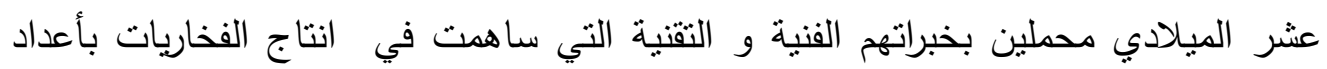

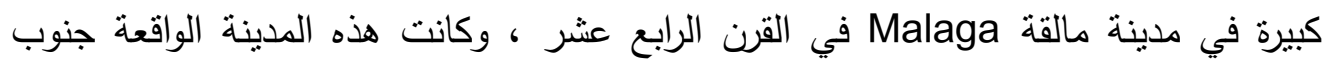

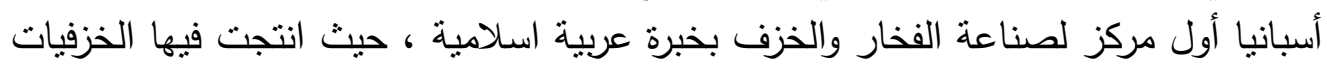

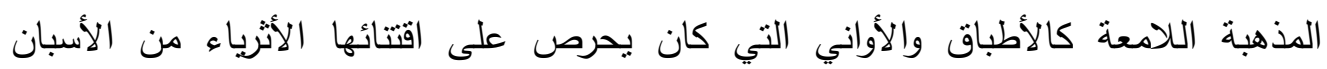
والإيطاليين بعد ذلك. وانتشر أسلوب الزخرفة بالبريق المعدني بين أرجاء العالم الإسلامي وأسبانيا وأصبح

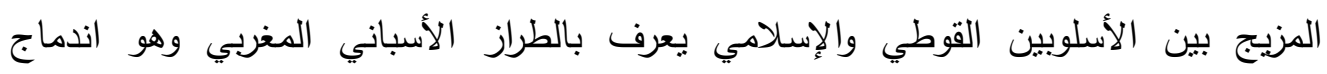
وانصهار رائع بين السمات والأفكار الثرق أوسطية والأوروبية .

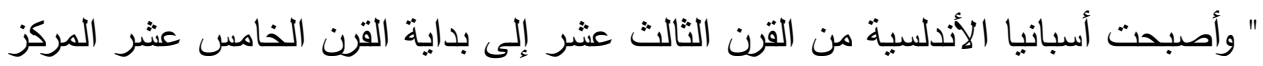

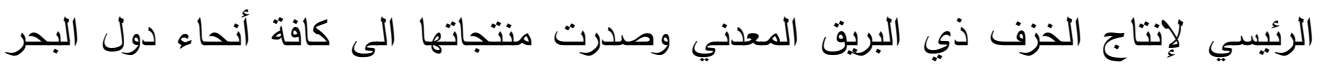

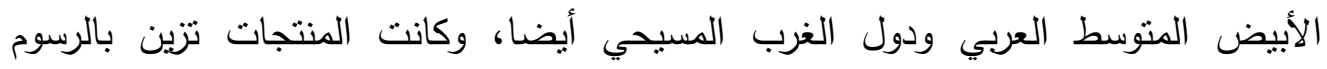

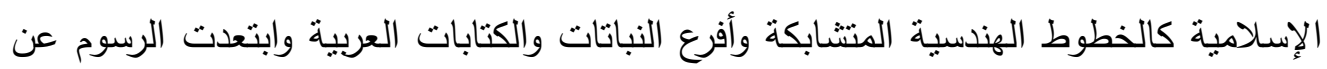

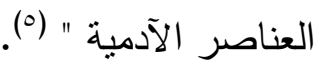


وتؤكد المنتجات الخزفية الايطالية فى هذا الوقت تأثرا كبيرا بالخزف الاسلامى وبالطرز الزخرفية المتمنلة بالتوريقات النباتية والكتابات العربية الا أن سرعان ما حل مكانها رويدارويدا رموزا ودلالات زخرفية وتعبيرية غربية نتيجة نهضة فنية انتشرت من ايطاليا الى باقى

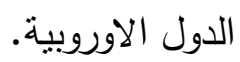

وفى تقنية المايوليكا تتم الزخرفة على الأسطح الخزفية المطبق عليها الطلاء الزجاجى القصديرى (الأبيض) بعد تطبيقه مباشرة على أسطح الأجسام الفخارية قبل الحريق باستخدام

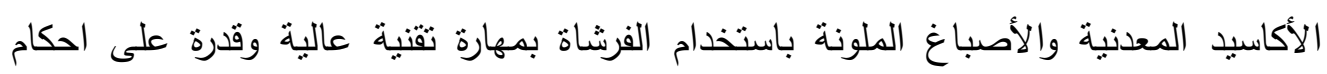
التصميمات الزخرفية والتعبيرية. وكانت المنتجات الخزفية الصينية البيضاء ( البورسلين ) في ذلك الوقت من المنتجات

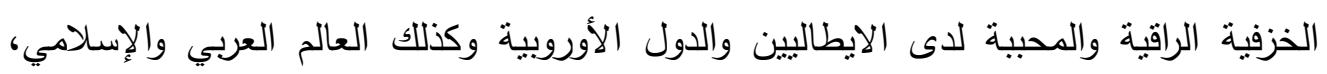
وتتمبز أجسامها البيضاء بإمكانية الرسم والزخرفة عليها بالألوان المختلفة مما بظهر جماليات

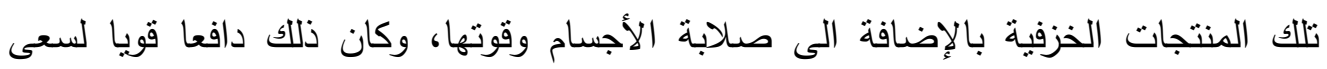
الخزافين الأوروبيين وخاصة إيطاليا الى تقليد الخزف الصيني، حيث كانت الطينات الجيدة للتشكيل في ذلك الوقت حمراء مما أدى الى تكسيتها ببطانات بيضاء (ملاط) لتكون أرضية بيضاء يمكن تزيينها وزخرفتها بالألوان من الأكاسيد المعدنية والأصباغ المختلفة، وما أن تم اكتثاف الطلاءات الزجاجية القصديرية خلال الحضارة الإسلامية أدى الى نطور أساليب

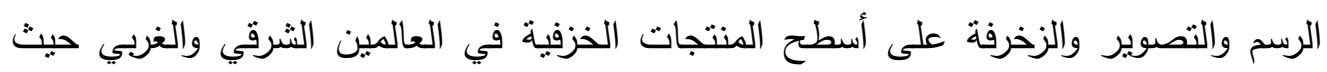

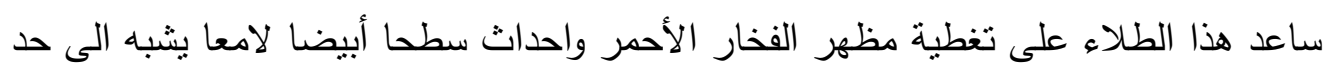
كبير الخزف الصيني، كذلك أكسيد الكوبالت الذى نم اكتثافه أيضا ساعد على تطور أساليب الزخرفة وولادة تقنية المايوليكا التي أتاحت للخزافين والمصورين المسلمين والايطاليين في ذلك الوقت من تحقيق قيما جمالية وتعبيرية على أسطح المنتجات الخزفية. وفيما يلي عرض مختارات متنوعة من منتجات الخزف خلال عصر النهضة والتي تعكس الترابط بين التصوير والمعالجات الجمالية لأسطح المنتجات الخزفية والتي تبرز القيم الفنية والتعبيرية لهذه الحقبة الذهبية في تاريخ العالم الغربي. 


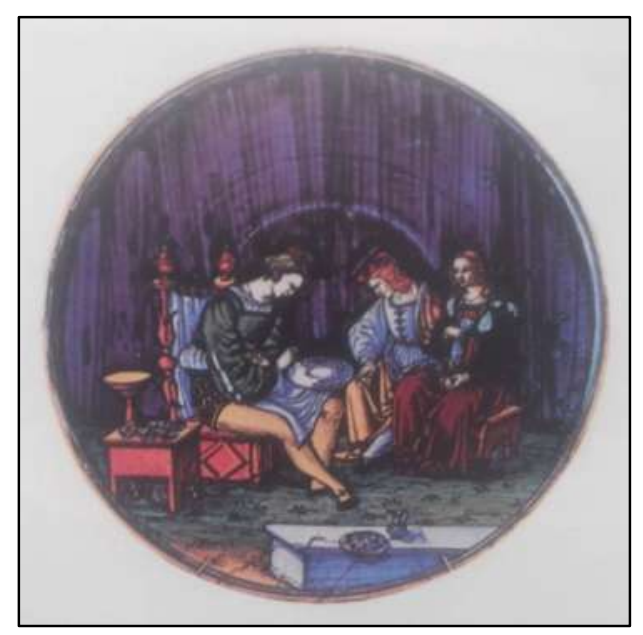

شكل رقم (1) 'كافاجولو Cafaggolo: طبق مزخرف بالأكاسيد الملونة بالكوبالت والصبغات الحمراء

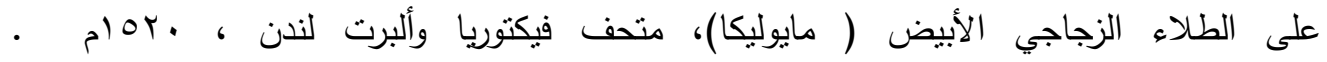

\section{توصيف العمل وتحليله شكل رقم (1) :}

العمل يصور فنان جالس يقوم بالرسم على طبق خزفى صورة تذكارية لرجل وأمرأة جالسان بمجاورة

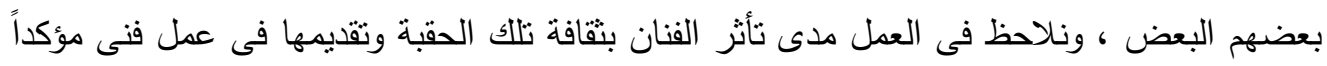

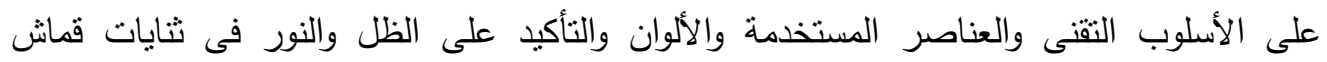

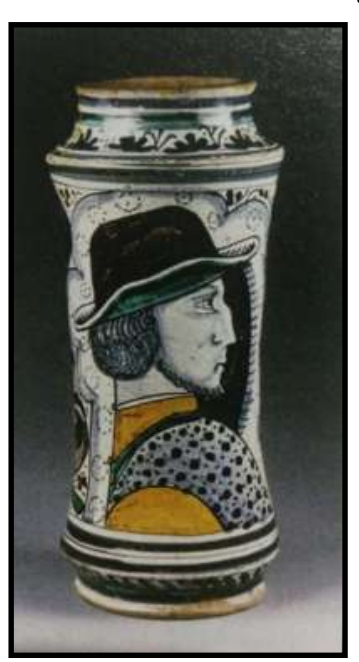
الملابس ليبدو العمل فى النهاية مفعم بالتجسيم والبروز •

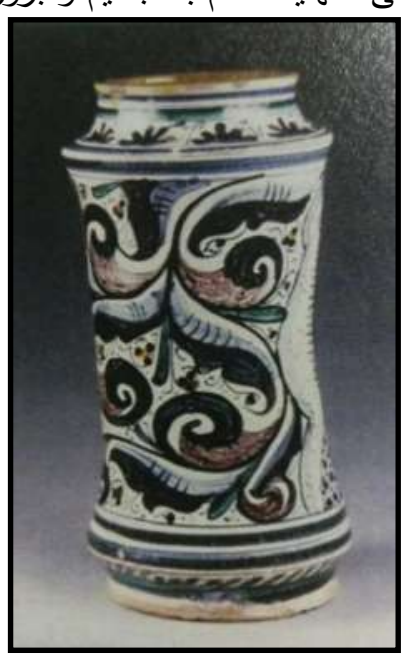

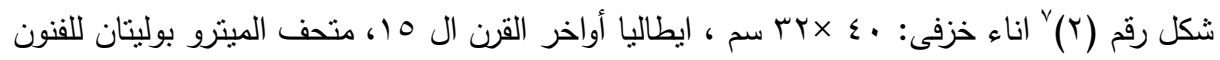




\section{توصيف العمل وتحليله شكل رقم (Y) :}

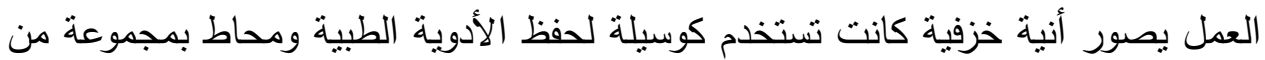

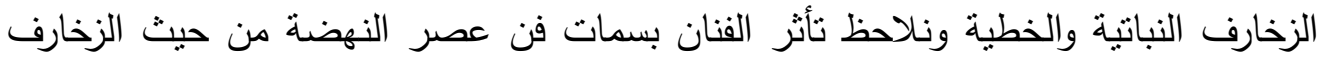

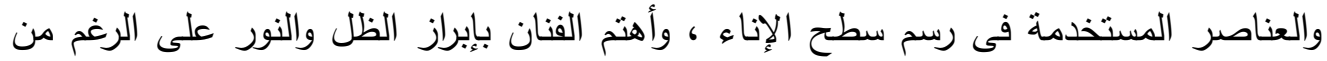
قتامة الألوان ليؤكد على قيمتها المعنوية .

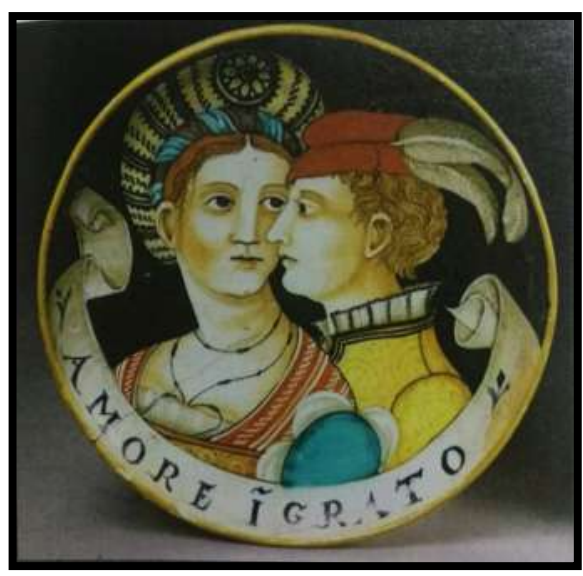

شكل رقم (r) طبق من الخزف مزخرف بالأكاسيد الملونة على طلاء زجاجى أبيض (مايوليكا) ،

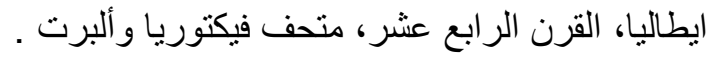

\section{توصيف العمل وتحليله شكل رقم ( r ) :}

يصور العمل رجل وأمرأة ويكاد يصور زكرى عائه رومائلية لزوجين ويحاط بصورتهما عبارة

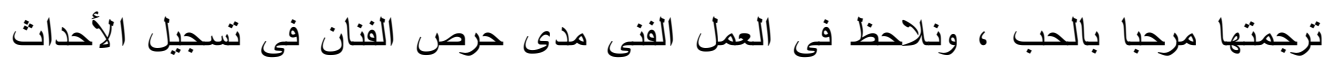

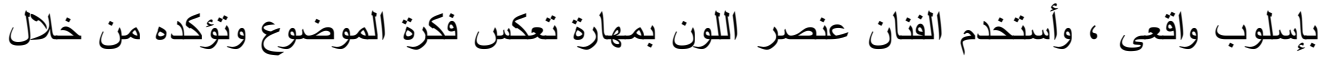
زخارف الملابس والقبعات التى توجد على الرأس إلى جانب إظهار ملامح الوجه ونس وتفاصيله .

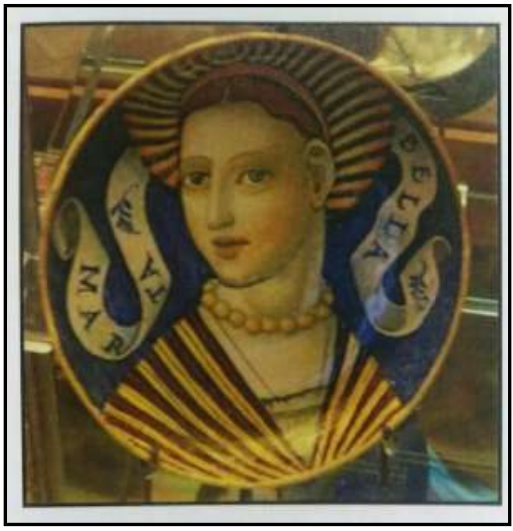

شكل رقم (ع) "ألفارو بوناليا (Alvaro Binaglia) ): طبق من الخزف المزخرف بالأكاسيد الملونه

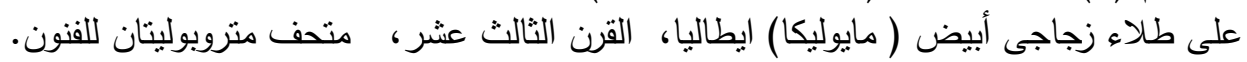




\section{توصيف العمل وتحليله شكل رقم ( ع ) :}

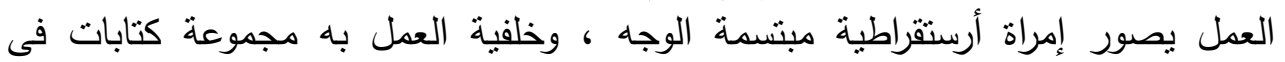
مسارات خطية ، وهذا العمل يدل على مدى إهتمام الفنان بالحفاظ على القيم التعبيرية مؤكدا على ذلك من خلال عنصر اللون والخطوط المسنقيمة سواء فى الملابس التى نرتديها الفتاة أو الفي

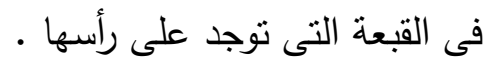

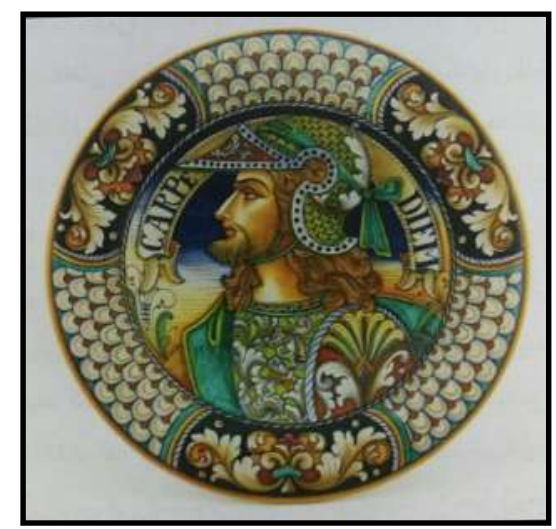

شكل رقم (0)' طبق من الخزف مزخرف بالأكاسيد الملونة على طلاء زجاجي أبيض ، القرن الخامس عشر ايطاليا عصر النهضة

\section{توصيف العمل وتحليله شكل رقم ( 0 ) :}

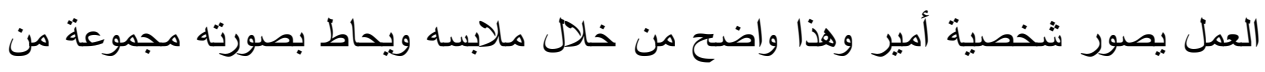

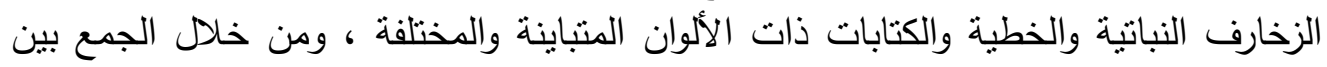

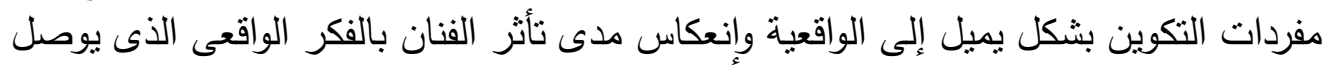

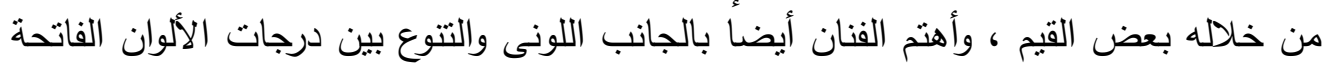

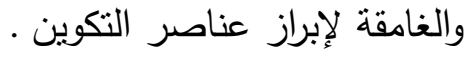

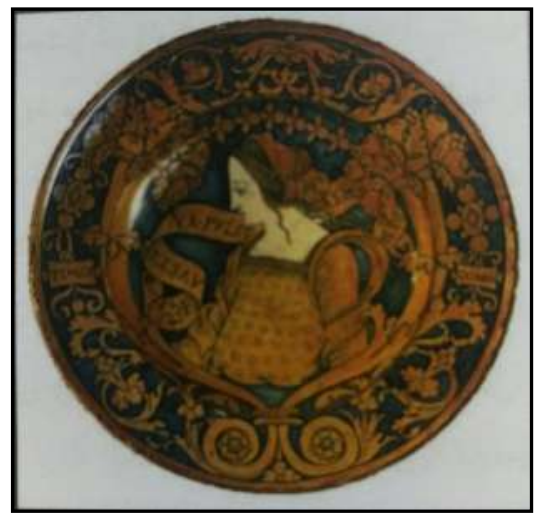

شكل رقم (؟)" طبق من الخزف مزخرف بتقنية المايوليكا والبريق المعدني على طلاء زجاجي أبيض، عصر النهضة، القرن ال 10، متحف المنروبوليتان للفنون 


\section{توصيف العمل وتحليله شكل رقم ( 7 ) :}

العمل بصور فتاة محاطه بمجموعة من الزخارف الثعبية ذات الألوان القاتمة ، وأستعان الفنان فى هذا العمل بالوحدات الزخرفيه النباتية ليكون بها موضوعاً غاية فى الجمال والحفاظ الجها

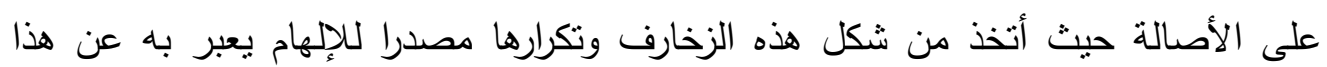
الموضوع والذى بعكس ثقافة الفنان المتأثره بتلك الفترة الزمنيه .

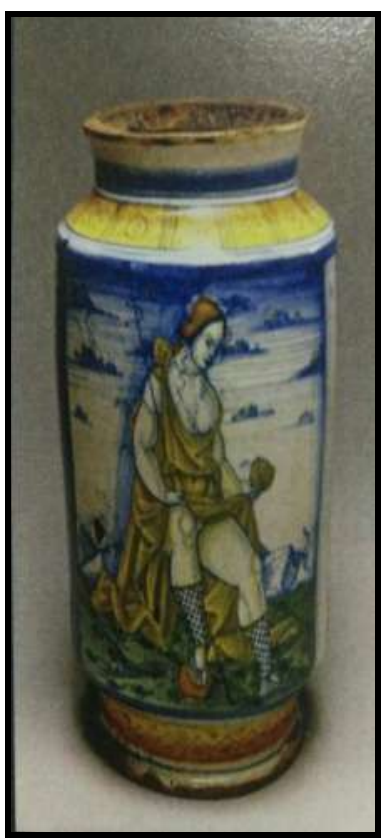

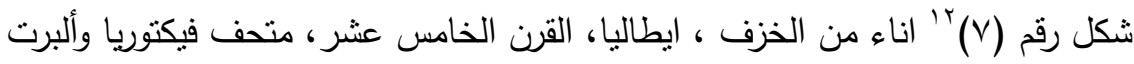

\section{توصيف العمل وتحليله شكل رقم ( V) :}

العمل يصور سيدة تجلس على صخرة فى بيئة يحيطها المساحات الخضراء ، وترفع ردائها بإحدى يديها واليد الأخرى تمسك بها جزء من الرداء ، وتظهر خلفية العمل بها مساحات خضراء وسماء وسحب زرقاء ، ونلاحظ فى هذا العمل مدى تأثز الفنان ببيئته التى لتى يحاول من خلالها أن يعكس طبيعه الحياة فى تلك الفترة مؤكداً على تلك القيم اللونية حيث مدئ أستخدم ألوان زاهية تبرز الموضوع وتؤكد الفكرة وعناصر التكوين . 


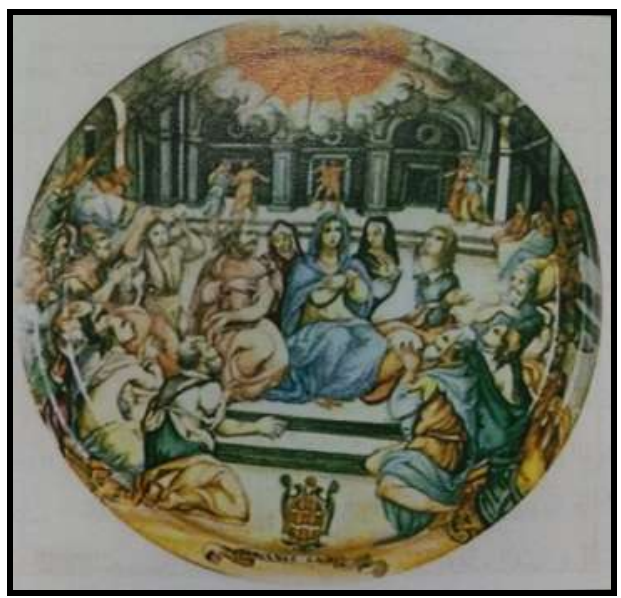

شكل رقم (^)" طبق من الخزف مشهد من دينيز فلورنسا ، منفذ بتقنية المايوليكا على الطلاء

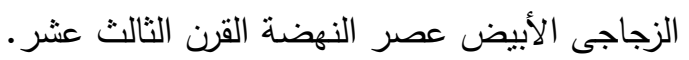

\section{توصيف العمل وتحليله شكل رقم ( 1 ) :}

يصور العمل مجموعة من الثخوص لرجال ونساء جالسون فى قصر ويبدو وكأنه الملك وبجاوره زوجته ويحيطهم مجموعة من الأشخاص فى حالة من التوسل والرجاء ، والعمل لا لاهن

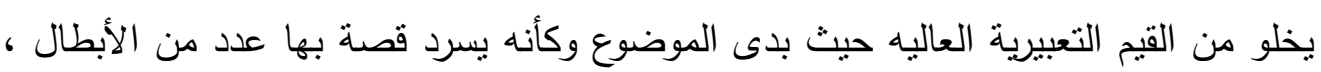

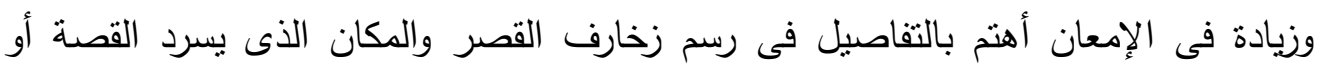

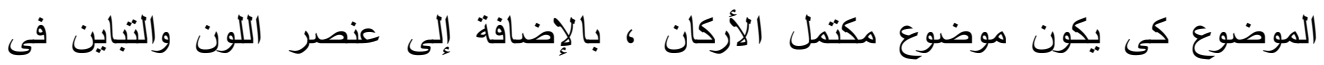

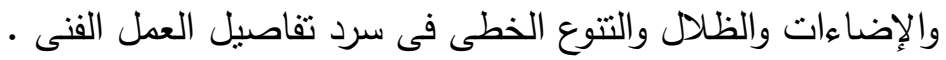

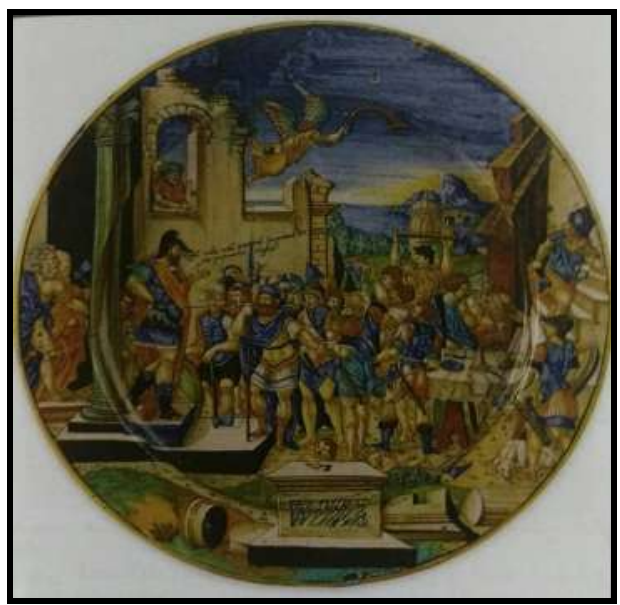

شكل رقم (9)' فرانثيسكو شانتو (Francesco Xanto) ، طبق من الخزف الأبيض الإيطالي،

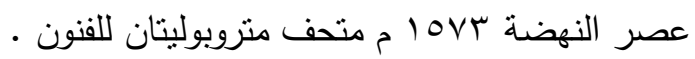




\section{توصيف العمل وتحليله شكل رقم ( 9 ) :}

العمل يصور معركة حربية حيث القائد يحيطه العساكر لاخذ التعليمات فى وضع دئ متأهل،

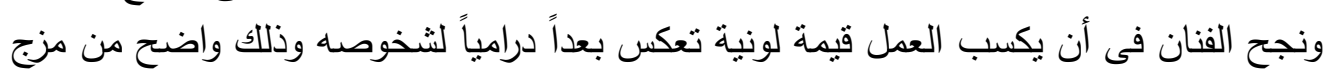

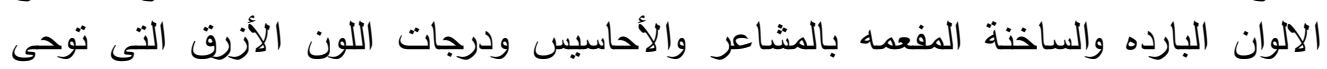

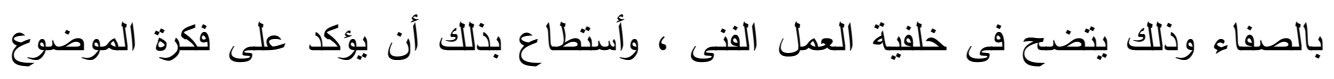

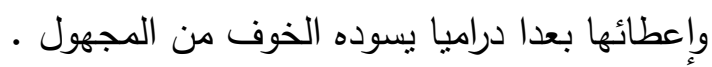
نتائج البحث

1- - هناك تتوع لخامات وتقنيات التصوير على الأسطح الخزفية فى فترة عصر النهضة .

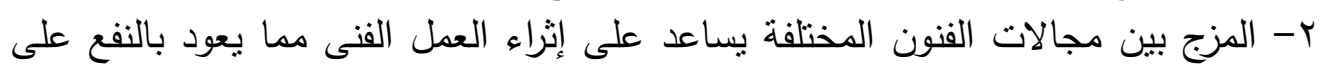

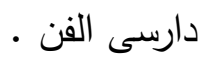

ب- وجود قيم تعبيرية متتوعه ومختلفة على الأسطح الخزفيه فى فترة عصر النهضة . توصيات البحث

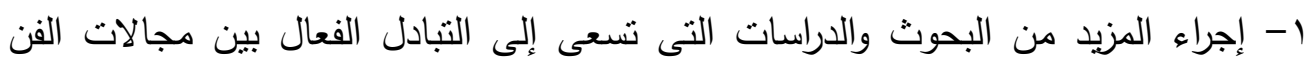

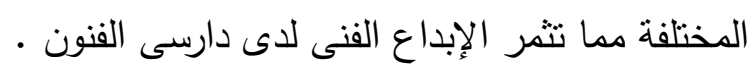

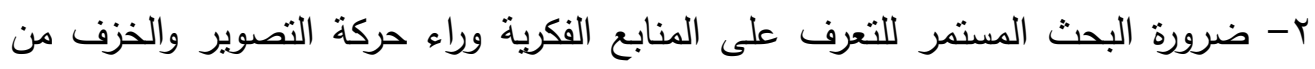

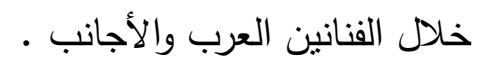

r- إتاحة فرصة التجريب المرتبطة بالإبداع لدراسى الفن من خلائ خلال المفردات الدراسية . ع - ضرورة الربط بين مجالات الفنون المختلفة . 


$$
\begin{aligned}
& \text { 1 - محسن عطية: القيم الجمالية في الفنون التشكيلة، دار الفكر العربي، القاهرة . . . ؟. }
\end{aligned}
$$

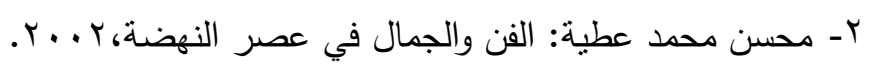

$$
\begin{aligned}
& \text { r- فنون عصر النهضة، الباروك. }
\end{aligned}
$$

عـ نعمـت اسـماعيل عـلام: فنـون الغـرب فـي العصـور الحديثة، القـاهرة - دار المعـارف، الطبعـة

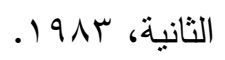

هـ هند جمال إبراهيم: تقنيات وجماليات طراز الخزف المغربي الأسباني في الفترة من ال قرنسا ا1 ام وأثزها في انتاج خزفيات معاصرة، رسالة ماجستير غير منشورة، كلية التربية الفنية،

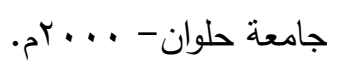

6- http://www.oxfordartonline.com/page/renaissance-art-and-architecture.

7- http:/en. Wikipedia. Org/wiki/Hisano- Moresque.

8- Nino Caruso: Decorazione ceramic, Editore Ulrico Hoepli Milano,1984.

9- Piccolo Passo, Cipriano: The three books of potter's arts, London; Victor and Albert Museum, 1934.

10- Thomas Shader pottery decoration- guptill - publications - New York -1976.

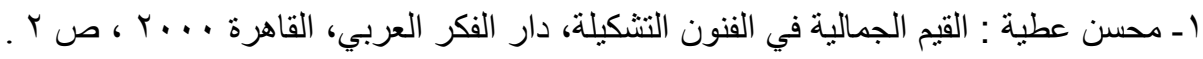

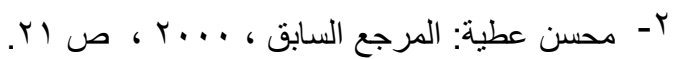

3. http://www.oxfordartonline.com/page/renaissance-art-and-architecture

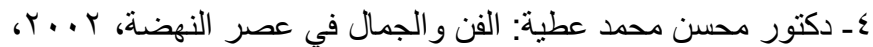

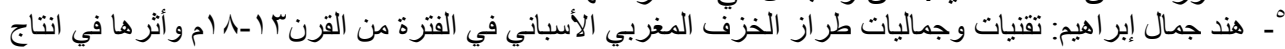

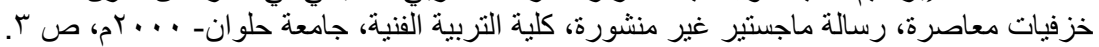

2- Tomasshaderpotterydecoration-guptill-publications - New York-1976-p94 .

6- Nino Caruso: Decorazione ceramic, Editore Ulrico Hoepli Milano,1984, p50

7 - Piccolo Passo, Cipriano: The three books of potter's arts, London; Victor and Albert Museum, 1934, p30.

8 - Piccolo Passo, Cipriano: The three books of potter's arts, London; Victor and Albert Museum, 1934, p30.

9 - Piccolo Passo, Cipriano: The three books of potters arts,London; Victor and Albert Museum, 1934,p30.

10 - Piccolo Passo, Cipriano: The three books of potter's arts, London; Victor and Albert Museum, 1934, p48.

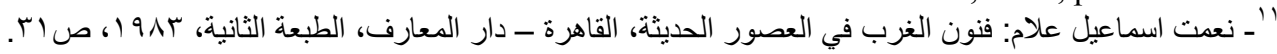

12- Piccolo Passo, cipriano: : The three books of potter's arts, London; Victor and Albert Museum , 1934 , p43

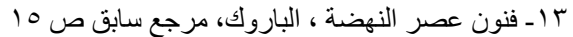

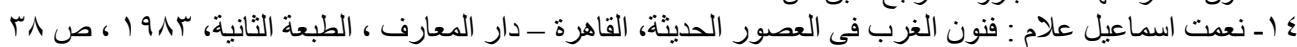

